\title{
Open Value Creation
}

\section{A Framework for Open and Collaborative Value Creation Concepts}

\author{
Daniel Schlagwein', Kai Fischbach', Detlef Schoder', Stefan Bartsch ${ }^{2}$ \\ ${ }^{1}$ Seminar für Wirtschaftsinformatik und Informationsmanagement, \\ Universität ₹u Köln \\ 2Institut für Wirtschaftsinformatik, Philipps-Universität Marburg
}

\section{Introduction}

In medieval times, experts in alchemy and other disciplines believed in secrecy being the key element of their scientific success and in hiding their results from curious eyes (paradigm of closedness). This principle changed with the advent of the European Renaissance around 1600, when the modern universities got established: Scientists published their findings for others to draw on them in an open science landscape (paradigm of openness) (David 2005). While openness describes the academic work of today, the classical assumption in the business world is still that internal resources and knowledge should be protected to serve as the foundation for the firms to create added value (Schumpeter 1942). In recent years, we see more and more exceptions from the paradigm of closedness in the business world: Alternative concepts of what we label "open value creation" are arising.

While there is a lot of research on specific open phenomena and concepts, we could not find a framework or meta-term that integrates all of these concepts. The first aim of this paper is to define "open value creation", and propose it as such a meta-term. The second aim is to identify open value creation concepts and connect them in a conceptual framework, based on an extensive literature review and following taxonomy building guidelines. By doing so, we hope to better integrate open value creation concepts and make them more accessible for meta-research. The paper concludes with a brief summary and discussion of the findings. 


\section{Openness and open value creation}

The term "open" has been used on several occasions in the history of IS practice and research. In the 1980s "open systems" got established, that allowed, in contrast to the proprietary systems of the Mainframe area, to run portable software on different hardware via standardized UNIX operating systems (Chau and Tam 1997). "Open" was understood as the ability to combine a broad range of software with a broad range of hardware. Since the 1990s, software developers use "open source software development", a concept allowing anybody interested in a software to contribute to its freely available source code via Internet platforms (Perens 1997, Raymond 1997). In this way, ideas and knowledge of many developers are combined with a broad base of source code. Since the 2000s, R\&D departments are increasingly taking advantage of a concept coined "open innovation" (Chesbrough 2003, Chesbrough, et al. 2006) by systematically searching for and internalizing external innovative ideas (or searching for externalizing options for internal ideas). This allows for a variety of external (internal) inventions to be combined with internal (external) development capabilities. We conclude that the attribute "open" in the context of our discipline describes the enabling of the combination of resources (information, knowledge, and infrastructure) from different entities, usually through IS-based platforms.

With regard to economic theory, the open innovation concept (looking for valuable contributions outside the firm's boundaries) is consistent with the Relational View (Dyer and Singh 1998), a specific theory within the Resource Based View (RBV) (Barney 1991, Wernerfelt 1984). The RBV focuses on firm-owned internal resources. The Relational View explains why knowledge sharing, and complementary assets (Teece 1986) can also be a source of a firms competitive advantage (Dyer and Singh 1998). From the scope of IS research, the relevant resources to be shared/exchanged (or not) between entities are information resources. The following information resource definition is derived from Levitan (1982): An information resource represents information which is economically relevant and inter-subjectively repeatedly applicable.

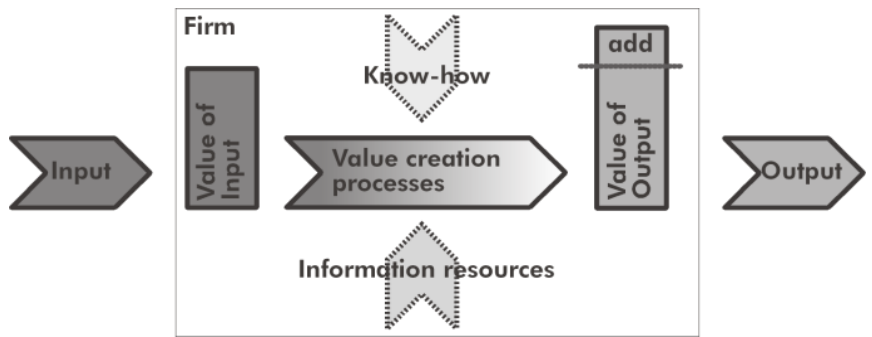

Figure 1: Value creation of a firm, know-how, and information resources

We consider both, information resources (i.e. explicit information), and tacit knowledge (e.g. ideas, solution knowledge). Tacit knowledge can be described as know-how, or "sticky" information (von Hippel 1994), that is embedded into per- 
sons or processes. To create value, know-how (of internal persons/agents) has to be combined with internal information resources (see Figure 1). Closed value creation describes the case of firm's employees using firm's information resources.

Within open innovation and the Relational View, two additional forms of value creation are taken into consideration (see Figure 2): In this view, a firm's agents/employees can use external information resources or agents of partners can use internal information resources. This value creation could be described as partly external. The potential for finding a valuable combination of information resources and know-how increases exponentially with the number of information resources available to agents (i.e. external-internal or internal-external combinations). Obviously, the information in question has to be brought into an explicit form and made available. It is depending on the dominant regime of appropriability (Teece 1986), whether both partners find it to be beneficial to exchange information with each other.

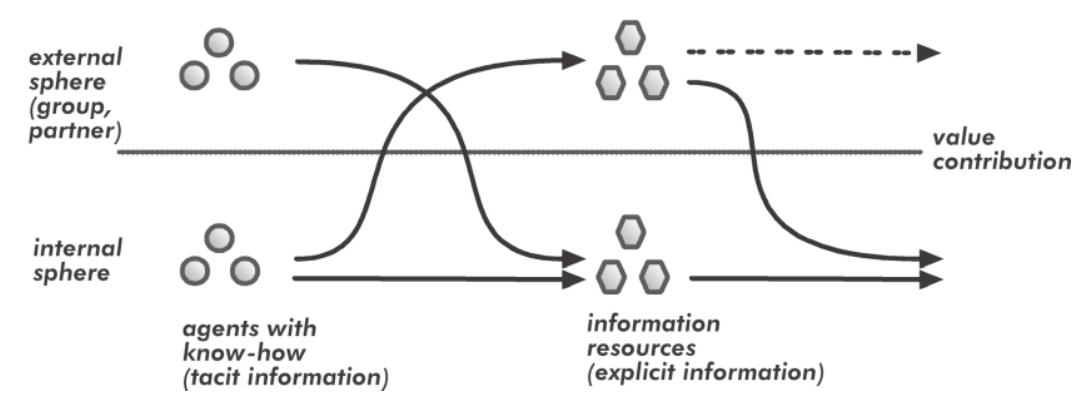

Figure 2: Internal and external value creation contributions

The open innovation concept and the Relational View focus on relations to external firms and organizations. The firm in question has to establish a legal relation (contracts, licenses) with them. However, in an increasing number of cases, we see externals (often end-users) using and contributing to a firm's value creation, without any or with fully standardized legal arrangements ("general terms and conditions"). For example, the arguably most popular social network Facebook does not buy its end-user data from any organization: The end-users are contributing the profile information themselves, even for free. Furthermore, in May 2007 Facebook opened its APIs (application programming interfaces) to third-parties in order to allow them to develop Facebook-applications based on this data. A lot of such applications (or "widgets") have been created by thirdparty-developers. While more users make the Facebook platform more attractive to developers, more applications make the platform more attractive to users. This is due to direct and indirect network effects and positive feedback (please refer to Arthur 1996, Farrell and Saloner 1986, Katz and Shapiro 1985, Shapiro and Varian 1999). Facebook's strategy of effectively opening it's platform and lowering it's regime of appropriability (in the sense of Teece 1986) - resulting e.g. in a massive 
rise of Facebook's market value - can not be fully explained with the traditional (resource-based) view on how to handle (information) resources, as this view suggests that only protected rare resources can contribute to sustainable value creation and competitive advantages (Barney 1991, p. 105-107).

For our argument transaction costs, the costs connected to any exchange between parties, have to be taken into consideration. These costs constitute the main reason why hierarchies (firms) exist in addition to market exchange (Coase 1937). The broadband Internet significantly lowered the transaction costs for the exchange of information. This becomes even more relevant, as an increasing number of people contribute ideas and contents to the "social web", or the "web 2.0" (a term usually attributed to O'Reilly 2005). With regard to information resources, the Internet offers an addition to hierarchies and market exchange: It enables social and open collaboration and information sharing in networks of unlimited numbers of agents. Contributions, relations, and transaction of this form are associated with no or negligible costs, as Benkler points out (Benkler 2002, Benkler 2006). Many cases illustrate, how valuable those open contributions are: Facebook, Google (Open Social), Apple (App Store), IBM (open source development of Linux), and Wikipedia are just the most prominent of many more examples (Tapscott and Williams 2006). Contributions of knowledge and information from parties, with which the firm has no individual legal arrangement, add another dimension to the model: the "open" sphere (see Figure 3).

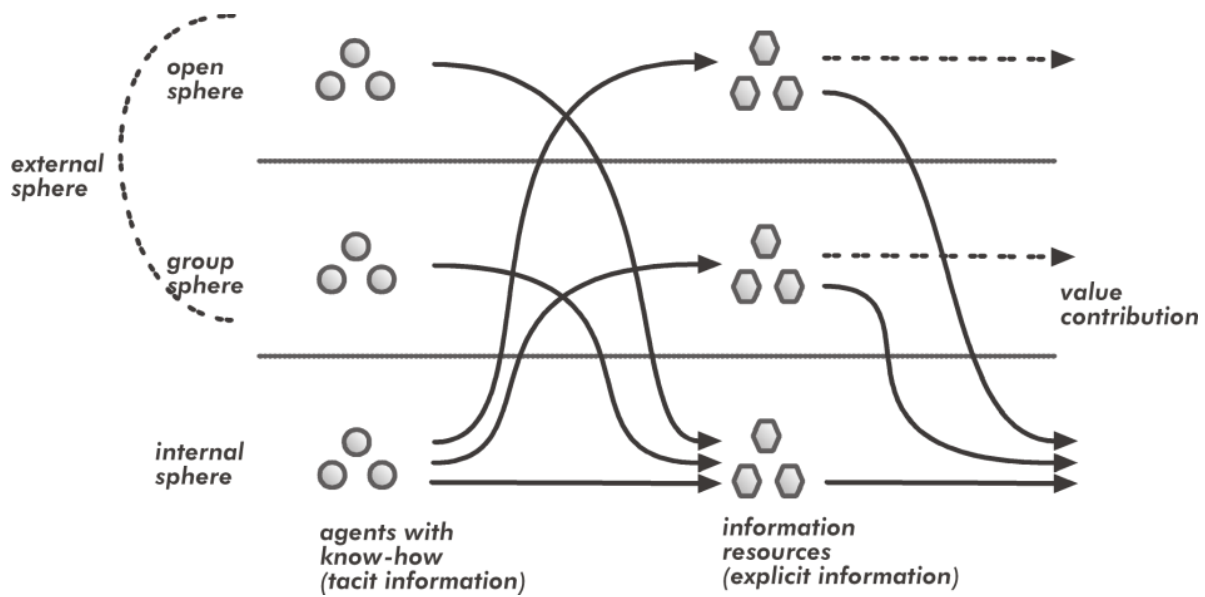

Figure 3: Internal, group, and open value creation contributions

The potential for value creation - valuable combinations of agents' know-how and information resources - is the greatest, if all possible combinations of agents and resources are enabled. Still, this opening of resources will usually lead to weak regime of appropriability (Teece 1986) and will require the firm in question to find alternative ways to benefit from the created value. In both literature and business 
reality, we can find an increasing number of phenomena and concepts on how to enable (and benefit from) value created in connection with the open sphere.

We define openness as the concept of promoting agents with open access to information resources to enable contributions from a wide range of entities in a flat organizational structure; and open value creation as value creation based on the principle of openness, enabled through open, collaborative IS platforms. We prefer not to use "open value creation" instead of the term "open innovation" as a frame for these concepts for two reasons: Firstly, open value creation in the given understanding focuses on the "open" dimension (anybody), while open innovation focuses on formal partners. Secondly, the term "innovation" implies working on a new product or process that is significantly different from existing alternatives (Hauschildt and Salomo 1997). Some authors include both the core invention and its commercial exploitation in the use of the term (Roberts 2007). Still, even with the broader definition of "innovation" many open phenomena are contributing in other than "innovative" ways to the value creation of a firm. That is why we use the more general term "open value creation" here. Open value creation describes value creating processes that are enabled or enhanced by integrating explicit information (information resources) or tacit information (know-how) from external sources, formal partners, and independent contributors like end-users, through open, collaborative IS platforms.

\section{A classificatory framework for open value creation}

Given the above understanding of open value creation, we are building a conceptual framework in the form of a basic taxonomical structure on the base of an extensive literature review. Classification or taxonomy building activity is part of the enquiry-branch of Systematics, originating in the works of biologist Simpson (1961). Taxonomic groups categorize similar "taxa" for the identification of fields. Because of similarities between biological and socio-cultural systems, analogue taxonomy and classification methods can be used for objects of the organizational sciences (McKelvey 1978, McKelvey 1982). Gregor (2006) shows that this classification methodology can be applied not only on natural objects, but also on abstract entities (concepts).

Criteria to be fulfilled with a classificatory framework are (Doty and Glick 1994, Gregor 2006, McKelvey 1982, Ch. 6): 1. completeness (all relevant concepts are accounted for); 2. simplicity and clarity; 3. exclusiveness of classes; 4. understandability and naturalness; and 5. usefulness (for human understanding). The objective of creating a taxonomy of open value creation is to identify diversely labelled but substantially identical concepts, to group similar concepts to classes, to enable a comprehensive understanding of "open value creation" and thereby to provide a conceptual framework to make existing and future research in this area more integrative and accessible. 
Focusing on information, Figure 4 considers three ways for a firm to create value. Purely internal know-how and information resources can contribute to the value creation. Additionally, external contributions from partners (group) to the value creation of a firm are considered. Finally, open contributions are included in the depicted understanding of (open) value creation.

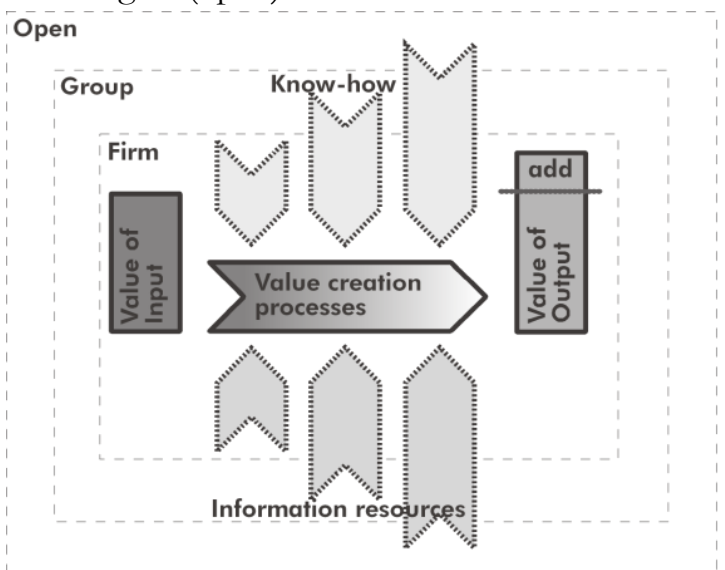

Figure 4: Internal, group, and open value creation contributions

To integrate open and external contributions, many concepts and methods are available. To develop classes of those concepts we choose the causa finalis of the firm (or other organization) for the concepts' use as the classification key. The relevant question is: "Which process in the value chain is supported by this open value creation concept?" This usually corresponds to different departments in a firm. The concept of a value chain within the company is usually attributed to Porter (1985). Similar to Bächle (2008), we use a simple value chain model as a frame for grouping open value creation here. Analysing the literature taking this view point, we identified three main classes of open value creation concepts that we need to distinguish: groups of concepts related to $\mathrm{R} \& \mathrm{D}$, to manufacturing/production, and to marketing/distribution (see Figure 5).

\subsection{R\&D-focused concepts}

While not calling it open innovation, already von Hippel (1978) proposes it as a R\&Dconcept. Allen (1983) describes an example of open innovation in pre-IT-times (the iron industry of $19^{\text {th }}$ century England) as "collective invention". The current usage of the term "open innovation" has to be attributed to Chesbrough (2003). The central idea of open innovation is that innovative ideas and inventions should be commercialized in the organizational setting where they are expected to create the most value. This is not necessarily where these innovative ideas arise. Therefore, firms have to actively look for external ideas that are fitting to their organization. In the current understanding of open innovation, three main 


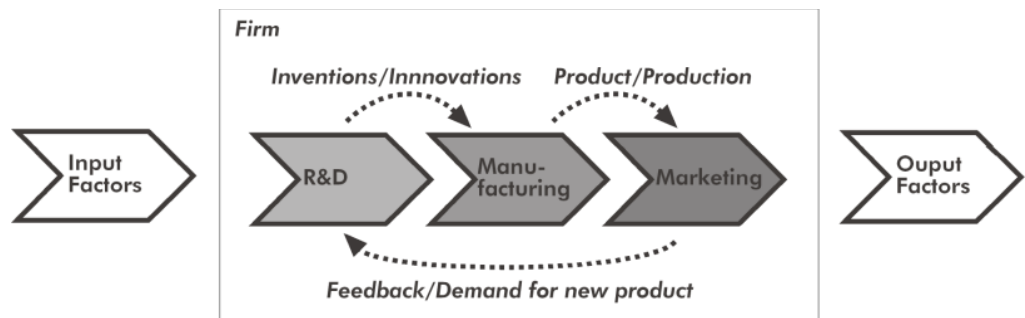

Figure 5: Main value creation processes within a firm

processes can be identified (Gassmann and Enkel 2006): "Outside-in" open innovation means that firms should not rely entirely on their own research, but look for external inventions; "Inside-out" open innovation means that internal inventions not directly contributing to the value creation of the company should be taken outside; Finally, "Coupled" open innovation describes the combination of both. Examples of the concept of open innovation put into practice are manifold and include Procter \& Gamble's Connect\&Develop (Huston and Sakkab 2006), IBM's Innovative Jam, and Dell's IdeaStorm. Chesbrough describes more open innovation efforts in detail (Chesbrough 2003, Chesbrough 2007, Chesbrough et al. 2006).

Web-based toolkits can be used for incorporating users in the R\&D process of a firm (Piller and Walcher 2006, von Hippel and Katz 2002). A toolkit is an application that consists of a set of design or development functions and is available to agents outside of the firm. Even the development of the toolkits themselves could be done by users (Thomke and von Hippel 2002). Toolkits offer several benefits: They help to generate and collect innovative ideas (Piller and Walcher 2006), allow companies to develop products more quickly or less costly (von Hippel and Katz 2002), and can lower the risk of failure of new products in development (Ogawa and Piller 2006).

Particularly lead users are using toolkits. The "lead user" concept is introduced first in von Hippel (1986). Lead users are valuable consumers, who are ahead of the mainstream with their needs and are mostly willing to contribute to new solutions, if they are enabled to do so. Toolkits can support lead user identification processes (Piller and Walcher 2006).

At the border between $\mathrm{R} \& \mathrm{D}$ and marketing we find the concept of idea competitions (Leimeister et al. 2009, Walcher 2007). Idea competitions are Internet-based competitions set up to collect solution knowledge from costumers to improve the value creation of the firm. Idea competitions, toolkits, and the lead user method can be seen as core practices of the open innovation (Leimeister et al. 2009, p. 200).

\subsection{Manufacturing-focused concepts}

The term crowdsourcing, which has been receiving a lot of media attention, is first used in Howe (2006). Crowdsourcing describes a concept of outsourcing tasks 
usually being performed by employees to a crowd of Internet users in form of an open call (Brabham 2008, Howe 2008). Examples for this concept include Amazon's Mechanical Turk, where different firms offer micro-jobs (like tagging pictures), or Threadless, a manufacturer of user-designed t-shirts. Crowdsourcing has also been proven to work for non-commercial applications, as the reCAPTCHA case illustrates, where millions of users are contributing to the digitalization of books (von Ahn et al. 2008).

Open production processes have existed in the software industry already for many years. Far sighted pioneers like developer Linus Torvals recognized the possibilities of working together online and started the remarkable development of the Linux. This concept is well-known as open source programming (Perens 1997, Raymond 1997).

Benkler (2002) elaborates on the concept of what he calls commons-based peer production, or, with a slightly different meaning, "social production" (Benkler 2006). Benkler describes a democratic, peer-based value creation method without a paying firm. There is controversy, prominently the "Benkler-Carr wager" (Carr 2006), whether free, democratic, self-organized, "commons-based peer production" (Benkler) or commercial, "incentive-driven end-user production" (Carr) proves the more powerful concept. While this is still to be decided, we can subsume both phenomena here, as they have the common characteristic to incorporate agents from the open sphere for production and manufacturing purposes. A showcase examples of peer production is the encyclopaedia Wikipedia - leading Tapscott to call the whole production idea "wikinomics" (Tapscott and Williams 2006). Wikipedia is the by far most used encyclopaedia - it's purely user-contributed contents can match the quality of the famous Encyclopædia Britannica (Giles 2005), and it is constantly kept up to date by its users.

Another manufacturing-related concept is mass customization (Piller 2003, Reichwald and Piller 2006). Mass customization describes the tool-aided creation of customized products by consumers. The idea of mass customization is first described in Davis (1987), but Pine (1993) contributes most to the recognition of the concept. The two basic criteria define mass customization: Firstly, consumers are given the technological ability of customizing products. Secondly, those individualized products still have to be producible at the price of mass productions (Kaplan and Haenlein 2006). To help customers to express their ideas on product design, manufacturing-focused toolkits can be useful here, too (Franke et al. 2008). These toolkits are used for configuring and confectioning existing products. In the industry for computer games there are many cases, where toolkits are on offer for customers to create in-game products, for example in the best-selling computer game, The Sims, or in the prominent virtual world Second Life. In both cases there is consensus in literature that this openness to end-user contributions has helped their respective successes. Physical products, like shoes from Nike or Puma are being mass-customized through toolkits as well. 


\subsection{Marketing-focused concepts}

Open value creation concepts are found in the marketing area, too. The term social commerce, coined by Rubel (2005), describes a concept of consumers gathering (and reaching them) in social networks and Web 2.0 environments (Bächle 2008). In those environments people can get or give advice, find goods and purchase them. The research process for consumers shrinks to one source, which brings together the knowledge and opinions of peers. Amazon was one of the pioneers in incorporating some social commerce functionality through user critics, user lists, and user ratings. StyleFeeder gives user lifestyle shopping recommendations based on the "similar taste" function. LastFM does the same thing for music. Both companies are taking advantage of the existing social networks by offering their services through popular widgets for the Facebook and MySpace websites.

The concept of agglomerating user knowledge to extract useful information or recommendations has been dubbed collaborative filtering (Goldberg et al. 1992). Through collaboratively filtering users can faster find products, which they are specifically interested in. In this way it facilitates the coverage of the "long tail" of nice markets (Anderson 2004). The wisdom of the many, the wisdom of the crowds, is supposedly superior to any other marketing knowledge, as Surowiecki (2004) points out.

Not yet in the focus of academic research is the concept of social media optimization (Bhargava 2006, Mühlenbeck and Skibicki 2007), which describes methods for generating publicity through social websites and online communities. Search engine optimization requires company websites to be optimized for the search engines (especially Google) to catch the attention of consumers performing a web search. Social media optimization intends to catch consumer's attention in social software platforms, e.g. through interlinking the website with those platforms ("share with"-buttons).

Social media marketing is sometimes described as a concept separate from social media optimization, as it focuses on marketing a firm or their products in the social web, instead of optimizing its own web-representation. This is done by directly interacting on e.g. the micro-blogging service Twitter, business-portals like Xing and LinkedIn, social websites like Facebook, user-content-focused websites like Flickr and YouTube, or in the "Blogosphere".

\section{Discussion}

This framework is surely not "finished": not the least because new phenomena and corresponding concept continuously arise in business reality. Still, we believe, the development of generic framework for "open value creation" as a whole school of concepts at this point brings several benefits for the research community. 
1. This article, as a framework and consolidating literature review, provides a mental concept for researchers, and makes this form of value creation more accessible for meta-analysis.(Schwarz et al. 2007).

2. We believe it is important in the education of Wirtschaftsinformatik (Information Systems) students to introduce open value creation as general way of "thinking beyond the borders of the organization". As these concepts are in most cases only possible with IT-platforms they constitute a responsibility of our discipline.

3. The new competencies and additional tasks of information managers can be more easily identified on the base of a generic understanding of open value creation, as these competencies and tasks (e.g. community design or management of collaborative technologies) seem to converge between the different open concepts.

A new generation, the post 1980-born "net generation" (Tapscott 2008), is growing up. This new generation is using (and contributing to) collaborative web platforms on a daily base. Taking this fact into account, the importance of research on open value creation concepts and methods cannot be stressed enough.

\section{References}

Allen RC (1983) Collective Invention. J. Econ. Behav. Organ. 4 (1):1-24.

Anderson C (2004) The Long Tail. Wired 12 (10):170-177.

Arthur WB (1996) Increasing Returns and the New World of Business. HBR 74 (4):100-109.

Bächle M (2008) Ökonomische Perspektiven des Web 2.0. WIRT 50 (2):129-132.

Barney J (1991) Firm Resources and Sustained Competitive Advantage. J. of Manage. 17 (1):99-120.

Benkler Y (2002) Coase's Penguin, or, Linux and the Nature of the Firm. Yale Law J. 112 (3):369-446.

Benkler Y (2006) The Wealth of Networks. Yale University Press, New Haven.

Bhargava R (2006) 5 Rules of Social Media Optimization (SMO).

http://rohitbhargava.typepad.com/weblog/2006/08/5_rules_of_soci.html.

Brabham DC (2008) Crowdsourcing as a Model for Problem Solving. Convergence $14(1): 75-90$. 
Carr N (2006) Benkler on Calacanis's Wallet. http://www.roughtype.com/archives/2006/07/benkler_on_cala.php

Chau PYK, Tam KY (1997) Factors Affecting the Adoption of Open Systems. MISQ 21 (1):1-24.

Chesbrough H (2003) Open Innovation. HBSP, Boston.

Chesbrough H (2007) Open Business Models. HBSP, Boston.

Chesbrough H, Vanhaverbeke W, West J (2006) Open Innovation - Researching a New Paradigm. Oxford University Press, Oxford.

Coase R (1937) The Nature of the Firm. Economica 4 (16):386-405.

David P (2005) From Keeping 'Nature's Secrets' to the Institutionalization of 'Open Science'. In: Ghosh Ra (Ed.) Code. Collaborative Ownership and the Digital Economy. The MIT Press, Cambridge.

Davis SM (1987) Future Perfect. Addison Wesley, Reading.

Doty DH, Glick WH (1994) Typologies as a Unique Form of Theory Building: Toward Improved Understanding and Modeling. Acad. Manag. Rev. 19 (2):230-251.

Dyer JH, Singh H (1998) The Relational View. Acad. of Manag. Rev. 23 (4):660679.

Farrell J, Saloner G (1986) Installed Base and Compatibility. Am. Econ. Rev. 76 (5):940-955.

Franke N, Keinz, P, Schreier M (2008) Complementing Mass Customization

Toolkits with User Communities. J. Prod. Innovat. Manag. (6):546-559.

Gassmann O, Enkel E (2006) Open Innovation. ZFO 75 (3):132-138.

Giles J (2005) Internet Encyclopaedias go Head to Head. Nature 438 (15):900-901.

Goldberg D, Nichols D, Oki BM, Terry D (1992) Using Collaborative Filtering to Weave an Information Tapestry. CACM 35 (12):61-70.

Gregor S (2006) The Nature of Theory in Information Systems. MISQ 30 (3):611642.

Hauschildt J, Salomo S (1997) Innovationsmanagement. Vahlen, Munich.

Howe J (2006) The Rise of Crowdsourcing. Wired 14 (6):176-183.

Howe J (2008) Crowdsourcing. Crown, New York.

Huston L, Sakkab N (2006). Connect and Develop. HBR 84 (3):58-66. 
Kaplan AM, Haenlein M (2006) Toward a Parsimonious Definition of Traditional and Electronic Mass Customization. J. Prod. Innovat. Manag. 23 (2):168-182.

Katz ML, Shapiro C (1985) Network Externalities, Competition, and Compatibility. Am. Econ. Rev: 75 (3):424-440.

Leimeister J, Huber M, Bretschneider U, Krcmar H (2009) Leveraging Crowdsourcing. JMIS 26 (1):197-224

Levitan KB (1982) Information Resources as 'Goods' in the Life Cycle of Information Production. JASIS 33 (1):44-54.

McKelvey B (1978) Organizational Systematics. Manage. Sci. 24 (13):1428-1440.

McKelvey B (1982) Organizational Systematics. University of California Press, Berkeley

Mühlenbeck F, Skibicki K (2007) Community Marketing Management. Books on Demand.

O'Reilly T (2005) What is web 2.0. http://oreilly.com/web2/archive/what-is-web20.html.

Ogawa S, Piller FT (2006) Reducing the Risks of New Product Development. Sloan Manage. Rev. 47 (2):65-71.

Perens B (1997) The Open Source Definition. http://ldp.dvo.ru/LDP/LGNET/issue26/perens.html.

Piller FT (2003) Mass Customization. Springer, Berlin.

Piller FT, Walcher D (2006) Toolkits for Idea Competitions. R\&D Manage. 36 (3):307.

Pine BJ (1993) Mass Customization. HBSP, Boston.

Porter M (1985) Competitive Advantage. Free Press, New York.

Raymond E (1997) The Cathedral and the Bazaar.

http://catb.org/esr/writings/cathedral-bazaar/cathedral-bazaar/.

Reichwald R, Piller FT (2006) Interaktive Wertschöpfung. Gabler, Wiesbaden.

Roberts EB (2007) Managing Invention and Innovation. Res. Technol. Manage. 50 (1):35-54.

Rubel S (2005) Social Commerce.

http://www.micropersuasion.com/2005/12/2006_trends_to_.html.

Schumpeter JA (1942) Capitalism, Socialism, and Democracy. Harper, New York.

Schwarz A, Mehta M, Johnson N, Chin WW (2007) Understanding Frameworks and Reviews. DATABASE 38 (3):29-34. 
Shapiro C, Varian HR (1999) Information Rules. HBSP, Boston.

Simpson G (1961) Principles of Animal Taxonomy. Columbia University Press, New York.

Surowiecki J (2004) The Wisdom of Crowds. Doubleday, London.

Tapscott D (2008) Grown up Digital. McGraw-Hill, New York.

Tapscott D, Williams AD (2006) Wikinomics. Penguin, New York.

Teece DJ (1986) Profiting from Technological Innovation. Res. Policy 15 (6):285305.

Thomke S, von Hippel E (2002) Customers as Innovators. HBR 80 (4):74-81.

von Ahn L, Maurer B, McMillen C, Abraham D, Blum M (2008) Human-based Character Recognition via Web Security Measures. Science (September 12, 2008) 1465-1468.

von Hippel E (1978) Successful Industrial Products from Customer Ideas. J. Marketing 42 (1):39-49.

von Hippel E (1986) Lead Users. Manage. Sci. 32 (7):791-805.

von Hippel E (1994) "Sticky Information" and the Locus of Problem Solving. Manage. Sci. 40 (4):429-439.

von Hippel E, Katz R (2002) Shifting Innovation to Users via Toolkits. Manage. Sci. 48 (7):821-833.

Walcher D (2007) Der Ideenwettbewerb als Methode der aktiven Kundenintegration. Deutscher Universitäts-Verlag, Wiesbaden.

Wernerfelt B (1984) A Resource-based View of the Firm. Strateg. Manage. J. 5 (2):171-180.

All web pages last accessed on September 18, 2009.

Journal codes according to AIS; journal abbreviations according to WoS. 